\title{
MALE CONSTRUCTIONS AND RESISTANCE TO WOMEN IN THE MILITARY ${ }^{1}$
}

\author{
Dr Nyameka Mankayi, Department of Psychology \\ University of KwaZulu-Natal
}

\begin{abstract}
Given that a masculinised institution like the military presents an exaggerated picture of hegemonic masculinities, and particularly emphasising physical fitness as one of the multiple ways in achieving masculinity, this paper provides an overview of how men in the military construct women's role in the military. This information is useful in understanding the gender power relations that make it difficult for most women in the military. The paper is based on a qualitative study of a diverse group of 24-33 year old male soldiers. Participants' stories reflected how notions of the strong body, particularly in the military context, which values toughness, contributes to masculinity. They further see women's expression of sexuality and their participation in command or combat roles as having dire consequences in terms of corrupting or weakening military deployment. This paper concludes that tackling traditional forms of male sexuality as they get played out in the military context involves the examination of dominant constructions of masculinity, and in particular discourses prescribing traditional sexual practices.
\end{abstract}

\section{Introduction}

Military structures of organisational authority are dominated, in general, by masculine principles and bureaucracy (Kanter, 1977). The relationship between masculinity and the military is portrayed in the literature as harmonious and mutually affirming (Enloe, 1988; Sasson-Levy, 2003). Enloe (1988) asserts that terms such as honour, patriotism, cowardice, bravery and duty seem so thoroughly tied to both the military and masculinity that it is hard to distinguish them as either militarist or masculinist. Militaries have long been identified and recognised as important sites for the construction of masculinities. This is not only because they

${ }^{1}$ This article is the result of research done for a doctoral degree awarded by Stellenbosch University. Thanks are due to Prof Tamara Shefer and Prof Tony Naidoo who supervised the entire doctoral study. The study was financially supported by a grant from the National Research Foundation. 
are populated by men or that they constitute a major arena for the construction of masculine identities, but also because they play a primary role in shaping images of masculinity in broader society (Barrett, 1996; Connell, 1992, 1995; Morgan, 1994; Woodward, 2000).

In military training, for example, recruits are systematically closed off from civilian life in an effort to transform 'boys' to 'men'. Woodward (2000:641) supports this when saying that the military attracts "recruits with the attributes suitable for molding into an identified finished product, the competent soldier". Recruits learn that there is a cult of toughness and masculinity traditionally associated with making soldiers out of civilians. They are taught that the proper response is to exhibit courage, endurance, toughness and lack of squeamishness (Barrett, 1996:132). Military training teaches that soldiering requires commitment and determination and that the defence of the country is touted as the reason for masculinity to be embraced, mobilised and emphasised in the military (Barrett, 1996).

Military training aims to produce 'warrior heroes'. Research on masculinity in the military suggests that the 'warrior' is still a key representation of masculinity despite far-reaching political, social and technological advances and changes. The concept of warrior hero has been crucial in the construction of notions of national security to facilitate the mobilisation of hegemonic masculinity (Lomsky-Feder \& Rapoport, 2003). As Woodward (2000:641) argues, this concept is a model of military masculinity:

The warrior hero is physically fit and powerful. He is mentally strong and unemotional. He is capable of both solitary, individual pursuit of his goals and self denying contribution towards the work of the team. He's also a bit of a hero with a knack of picking up girls and is resolutely heterosexual. He is brave, adventurous, and prepared to take risks. Crucially, he possesses the abilities to conquer hostile environments, to cross unfamiliar terrain, and to lay claim to dangerous ground.

In these conceptions the warrior hero is gendered and sexed as a man. Therefore, sexuality and masculinity intersect, and are drawn together in a practice where men conquer by sexual intercourse and expressing hegemonic masculinity (Lindegger \& Durrheim, 2001). This also suggests that a key symbol of masculinity is heterosexual practice. But considering the growing numbers of women in the military, a pertinent question for this paper is: "How do men construct female soldiers' role in the military considering that women are now in 'their 
environment'?" Williams (1999) argues that, despite the increasing number of women in the military, no other institution is more closely associated with masculinity. Of the twenty million members of the world's armed forces, an overwhelming majority are men (Connell, 2000). Soldiering and masculinity constitute ideals of manhood. Writing about the South African military, Cock (2001), for example, states that masculinity is linked to guns.

Given this background, debates about the expanding role of women in the military are the main focus of this paper. I shall first give the centrality of male bodies in the military, and then later raise concerns about women's bodies and their 'misfit' in the military. The way in which male and female bodies are constructed in the military, facilitates traditional male sexual practices which have been shown to further question the existence of women in the military. All this will be discussed below. Thereafter the methodological approach of this paper will be briefly discussed. Finally, the analysis of my interviews relating them to the literature to reflect on and contextualise these findings will be done.

\section{Masculinity, military and the body}

The notion of 'embodiment' is central to a number of contemporary theoretical perspectives and feminist writings that contribute to understandings of human subjectivity (Jung, 1996; Potts, 2001; Somerville, 2004). Connell (2000) argues that men's bodies are inextricably relevant and intertwined with masculinity. He further argues that social institutions and discourses give men's bodies social meaning. A range of bodily practices from the society - ranging across sport and sexuality - address or modify bodies. This view brings to focus the centrality of bodies in the military, in terms of the desired strong physique required to be a warrior.

For some men, the physical training that produces the physical fitness required by the military seems to be a way of reasserting their gender, and proving their masculinity (Cohn, 2000). For some, military service is an inherent part of maturation, a rite of passage to successful male adulthood (Klein, 1999) and it embodies codes of honour that stress a number of supposedly male virtues including willpower, honour, courage, discipline, adventurousness, independence and sexual virility. These attributes are all characteristics of hegemonic masculinity (Cheng, 1999; Martino, 1999). The demands of soldiering bring together these manly virtues and the concepts of bravery, fearlessness and persistence (Aids brief, n.d.). Attaining this masculine ideal depends on soldiers' physical fitness, strength and even emotional 'maturity'. The military-masculine ideology discourages military 
personnel from admitting they are emotionally vulnerable as this is potentially threatening to military morale, hence the ascendance of phrases such as "behave like a soldier" or "take it like a man".

\section{Military, femininity and body}

The opposite side of the coin with respect to the centrality of the body in masculine achievement is the way in which female soldiers are problematised in the military. Women have almost universally been excluded from combat (Carreira, 2006; Cock, 1992; Kümmel, 2002; Heinecken, 2000). In the first instance, their biological role (bearing children) and gender roles (raising and caring for children) were inhibiting forces. The traditional belief in both military and civilian spheres is that men defend the country, women and children. One of the key underlying arguments is that if women die in combat, there will be no one to fulfill their biological role. According to Steihm (1980:56):

New lives can be created, but it takes one woman to bear each child each year, while one man can father a larger number of children a year. Numerous women are essential to the replenishment of a population, but only a few men are required.

This seems to be a good argument for polygamy and the prospect of a patriarchal dividend for the successful surviving warrior. This is in line with sex role theory whereby men are seen as the only gender that should be placed in risky situations, and this emerges from the belief that women are the weaker sex while men are considered strong and brave (Agostino, 2003; Connell, 1995; Weitzman, 1979). Another common concern raised is that if women are in combat, men would concentrate more on defending them than on fighting their opponents. This would influence the operational effectiveness (Heinecken, 2000).

Women are described as not having the ability to perform military tasks that require a high level of muscular strength, such as, the carrying of heavy equipment (Cock, 1992; Heinecken, 2000; Presidential Commission, 1992). Countries such as the Netherlands, Denmark and Canada have never excluded women from combat, but there are very few women in the infantry and other combat corps due to the physical training requirements for entrance which seem to be difficult for women to pass (Presidential Commission, 1992). South Africa was no different, women were restricted from combat until 1996. However, Article 9 of the Constitution of South Africa (1996) states that women should be afforded equal opportunities in, and to, all roles. Therefore restricting women from combat denies 
them the right to equal opportunities in the military that may inhibit their access to experiences needed for professional growth.

Much as there is a commitment to integrating women in most militaries, the other implications reported are that sex and sexual difference may continue to challenge working relationships (Careira, 2006; Guttman, 1997). Worldwide, female recruits and officers are reported to have accused drill instructors and male officers of rape and sexual harassment. For example, female soldiers have made similar accusations throughout the US military (Chema, 1993; Guttman 1997). It is reported that in the US Army, sexual misconduct against women exists in the ranks, and the leadership condones or ignores various sexual practices.

In the SANDF, there is little data in this regard, but it is acknowledged as a problem by Sedibe (2000). She reported that $49 \%$ of both civilian and uniformed women in the SANDF had been subjected to sexist remarks. Heinecken (2000) confirmed that there are high incidents of sexual harassment reported by women in the military especially those in non-traditional positions (combat units) where men are in supervisory roles. She further argued that gender harassment is more prevalent than sexual harassment. This means that "lack of respect for the rank, authority or commands given by women constitute gender harassment. Sexual harassment includes a wide range of unwanted uninvited activities ranging from sexual favours to whistles" (Heinecken, 2000:97). Other national and international studies (though not in the military) also find that sex differences serve to clarify power inequalities in institutions (Collinson \& Hearn, 1994; Flood, 2000; Shefer, 1999; Van Wyk, 2004).

\section{Methodology}

This paper emerges out of a larger qualitative study on men in the military, which explores how they construct their masculinity and how this is interwoven with their sexual practices. The paper explores men's perceptions of women's role in the military and how this role intersects with masculine constructions. The paper presented is an outcome of an analysis and interpretation of 14 transcribed interviews with men in the military. A sample was drawn from the full list of students as all participants were enrolled in a tertiary institution pursuing a career in the military. Even though participants were students at the time of data collection, they have been in the military for more than four years. Participants were between 24 and 33 years old. All participants were junior officers, with ranks ranging from lieutenant to captain. 
Representativity during sampling is not regarded as crucial when doing qualitative research. However, diversity was taken into account, specifically when identifying and selecting the participants. Firstly, racial and ethnic diversity is central given the salience of race and ethnicity in the South African context. Secondly, diversity according to military rank and educational level was also taken into account but within the limitations of the student population at a junior level. The decision to interview participants from diverse backgrounds was based on the assumption that different experiences, predispositions and circumstances may have led to different constructions of masculinity and sexuality. A diverse sample facilitated the possibility of diverse stories being heard which could contribute significantly to the nature and content of future HIV/AIDS interventions. Although not all groups are represented, for example no Indian men approached agreed to participate, the sample of participants broadly approximates the SANDF's demographics. Four of the participants were Afrikaans speaking, two English, two TshiVenda one IsiSwati, one IsiXhosa, two IsSesotho, one Setswana and one IsiZulu speaking. Only three participants were married.

In-depth, individual interviews were the main form of data collection in this study as my interest lies in the participants' narratives, stories and how these reflect, reproduce or challenge broader discourses. The interviews were audio-taped and transcribed verbatim. The meanings drawn from the transcriptions were derived from repeated readings of the transcripts and were understood in terms of discourses. Hollway (1995) and Edley and Wetherell's (1997) interpretive discourse analysis were adopted in the analytic process of this study. Pseudonyms were used to identify participants.

\section{Findings and discussion}

Only two major themes emerged from the analyses that are directly relevant to the central question of this paper which is: What are the male soldiers' constructions towards female soldiers? The themes are discussed below.

\section{Women in the military: a challenge to masculinity}

A central thread during interviews regarding women in the military was the deeply entrenched and stereotypical constructions of gender roles. This places women firmly in caring roles while men take up particular subject positions in relation to the hegemonic masculinities and masculinities as warriors. Sex role gender theory and essentialist notions are thrown up by the excerpts through claims that by nature women are not aggressive. Therefore, they cannot be fighters and 
should not be in war (Agostino, 2003). Morgan (1994:166) argues that in the military gender plays a crucial part in determining "who does what" and "who is what". This is borne out by the way many of the participants referred to the opportunities granted to women to join the military. Asked how they feel about women joining the military, participants expressed a mixture of approval and discomfort around women's vulnerability. This is illustrated in the following extracts:

Mtobeli: I think ja, because there's... there's a lot of things in the military, ja, there are some things, which we see that women is gonna fit.

Thando: Its nice for... the fact that they are soldiers and the fact that opportunities are also given for them. But in my own own view I wouldn't appreciate it like I wouldn't eh advise maybe someone to join. I wouldn't want to see her get involved in military deployment maybe its my (stereotype), but I would prefer to see her working in the (unit). To be more diplomatic and I don't like the fact that, the environment we tend to deploy to... sometimes it turns to be risky especially accommodation. Ja, I think I'm more protective.

Similarly, Simon demonstrated the scenario in a risky environment:

[If] she has to be a platoon commander, where she has to take people to war and command them in battle, where she has to be the only lady among 35 people at the DRC, where there is no food, no toilet, no shower. And there you are lady, take control of this group. What is she going to do? Black men are more sexist than white men are. Black men don't want ladies bossing them around. Especially in the lower ranks, troops don't want ladies bossing them around. And what this lady is gonna do in the middle of the jungle with 37 men. Is she going to stand up and say Hey! you do what I'm going to tell you to do or else... or else what? Do you understand?

The excerpts from both Thando and Simon demonstrate the binary gender logic of male/female and protector/protected. They feel it is their responsibility to protect women; moreover, masculinity is supposedly overly concerned with the protection of women during warfare (Agostino, 2003; Connell, 1995; Foreman, 1999). Otherwise, if women join the military they are expected to prove that they have capabilities and strength to cope with the military environment which is constructed as a male domain, therefore inherently not for women. A further 
racialised or culture discourse is used to highlight uncertainty about having women in the military, as seen in Simon's excerpt. Some participants are concerned about women leaving their traditional roles. Sam, for example, contrasts women soldiers with the feminine ideal:

Sam: That womanly thing er walking like women, sitting like a woman, bend like. You can see, this is a soldier, this is a woman. So I think the military generally take[s] away some of the woman's, some of the woman's um, how can I put it...

Sam's position is that women are not organic soldiers therefore military women's femininity is questioned, with women viewed as behaving like men. He sees women's presence in the military as a challenge to their femininity, which even interferes with standard norms of masculinities. This argument is supported by Gerhard (another interviewee) who stated that he would love to see more women being feminine and not doing physical work which is part of soldiering and therefore not suitable for women. However, he acknowledged that the physical training gives women "nice bodies". This ambivalence is widespread:

Johan: Well, I think women in general in organisations have a lot to offer because they bring a very good balance to organisations. But I think the utilisation of women in the military should be managed very well. Er, and I think that they tend to push women into functions that are supportive instead of trying to do it scientifically. Cause in my career I've seen few women who are good fighters. I've seen few of them 'cause one was on my crew, a very good soldiering officer and I mean she will go far in her career. But, I agree with opinion that operationally and in training women in general are not conducive for healthy military um effectivity and for keeping a good discipline among the troops.

Johan further states:

Ja, what I'm, what I think is that when you have women in the military in command positions... um... I think when they are in administrative support roles you won't have that much of a risk. But if you have women in command, you must choose them very well. Women are such an issue in the military... um... you can't just choose any woman to take command, because you are looking at a tradition and men don't easily submit to any woman. So... they have to deal with the fact that they are physically not as strong, that they don't have as strong a voice. That they have, that they 
are more emotional. So women have a lot against them um compared to men in taking command. And I just think that in the military we need to make life easier for those women. And we need to look at the impact that their command will have on the troops involved. Um. Because the impact it has on men and the effectiveness of units on performance under training is huge. That's, that's something we should take responsibility for.

This participant draws from cultural discourses which view male bodies as compatible for war (Agostino, 2003). He further sees the women's participation in command or combat roles as having dire consequences in terms of corrupting or weakening military deployment. To put it simply, the suggestion is that in order to maintain effective military culture, women should be excluded because of the disturbance this brings to male-female power relations. There seems to be an unwillingness to obey women's leadership, as Johan puts it "men don't easily submit to any woman". Another expressed discomfort about women in the military is drawn from a discourse of women's liberation which seems to be detrimental to military effectiveness.

Simon: I have my reservation about that, not because of women but because how women are treated. Women are being given qualifications when they don't complete the same course that everybody else completes. You get female pilots that are damn good pilots. But there are a lot of females that are getting qualifications that they don't deserve. The last SA Soldier magazine was earmarked for women. There's... there's an Indian girl on the cover, she is a pilot. She got her wings... there was a big write up, she is so fantastic. She got her wings and that was a year ago. A month after that article was written, she flip herself on the runway. She put a plane on its back on a runway... Because, she is one of those where it was said we need an Indian girl pilot... She just got there as a political token.

This excerpt demonstrates the superiority of race and that of maleness. The implication is that there is inherently something wrong with representation across race and gender. The unspoken assumption from Simon's excerpt is the general incompetence of women. Simon elaborates on this women's liberation discourse that is enforced irrespective of women's perceived lesser capabilities in certain areas:

Simon: Guys carry their rifle sacks, guys carry their kits, guys carry their things, guys cook their food. We don't have females in our regiment 
because they don't make our selection process. But now the colonel, who was there before, said there would be female parachutists by the end of the year. He put two females on a course. They didn't make it on the course but they carried on, now that brings immediate resentment in us, because that you have to shit physically and mentally to be able to do that course whilst the girls just walks in "I'm a lady". Both those ladies refused to carry on. Because one was scared of heights and the other just could not carry on. Thus, the course commander was sent away from course because they said he is a sexist but the two girls wanted to come. Do you understand?

Int: Would you have said that is a minority?

Simon: It depends, if you take cores like Intelligence, there you need ladies, you need ladies in personnel. But the infantry you can't. For example in 2001 there was a platoon of ladies. OK but now the platoon of ladies they slept in separates rooms, separate shower separate messes because they are ladies. They don't do duties because they're ladies and that is too difficult, and they're ladies (Sounded annoyed). Do you understand? If they want to be infantry soldiers, then they must be infantry soldiers now the ladies have different PT test than men.

Simon's notion of differences in expectations, duties and concessions is based on gender. The discourse here is that women's inclusion in the military compromises standards of quality, masculinity and soldierhood. Similarly, Sam is of the opinion that women are given positions that they don't deserve and then men left in junior positions to do the entire job for them. A consequence is that men are then paid less.

Sam: And the men, my 2 IC must do her job. His name's not on the payroll to receive the same salary as that woman. He's not getting the salary for that.

It is not only women's biological and gender that are constructed as problematic in the military. Their sexuality also appears to provoke anxiety in male soldiers. 


\section{Women soldiers' sexuality: a challenge in the military}

As with other studies (Guttman, 1997; Carreira, 2006) a linkage between masculinity and the military stemming from deeply held notions equating masculinity and military, with sexual prowess, was found. By this, I mean that not only stereotypical gender role construction was found, but how women should behave sexually. For example, they question the real reason why and the type of women who joins the military. They expressed particular discomfort about the sexual practices of women on deployment and attending military courses. This is evident in the following extracts:

Mtobeli: For things like relationships, it's not good in the military for women, especially in combat. For them to be in combat for me, I don't think so. Because let's say, [your wife is] moved from Cape Town, with a ship to India... it's possible that your wife will get tempted somewhere on the way. She will want security, then maybe take one of the guys.

Thando: Say for instance you have a relationship and then she goes on military deployment, chances are she might have a relationship there. All military ladies are like... when they go on deployment they start relationships.

As reflected in other studies (Holland et al, 1991; Hollway, 1989, 1996; Lesch, 2000; Shefer, 1999; Van Wyk, 2004), in general, female soldiers are viewed negatively and accused of being immoral if they engage in extramarital sex or take multiple partners, so that women 'who submit' to men are viewed as 'loose'. The salience of moral judgement of women who step out of traditional female sexual roles or their roles as monogamous wives is more than evident here:

John: We were talking about women and how they are. This guy told me that $90 \%$ of the ladies they also slept with several guys while being on course. I don't know why but, I've also experienced that er there's a loose, a loose tendency and ladies will easily submit to or having sex with with guys, even, even when they're married. Um, I can't say why, but um there's a there's an easy tendency to have sex with someone (inaudible) I mean a married girl's on course, they're married they still have sex with another guy.

Female soldiers are labeled as state mattresses (state mattresses are perceived as cheap and affordable to anyone, therefore everybody can sleep on that 
mattress). There is clearly a construction of military women's sexuality as deviant. This is emphasised by Sam who compares their behaviour with that of civilian women in order to problematise their sexual practices:

Sam: As I said earlier I saw a lot, I mean a lot, of women in uniform, in the military getting involved in intimate relationships, quite easily, you understand. I don't know why, but quite easily. And you will see when you go to a function or a social event, take women soldiers and civilian ladies together with men [and] you'll see who's the woman... misbehaving the most. Not like in bad manners but in who is like that wilder, that womanly thing er walking like women, sitting like a woman, bend like. You can see, this is a soldier, this is a woman. So I think the military generally take away some of the woman's, some of the woman's um, how can I put it?

Women soldiers' sexuality is therefore constructed as breaking from the traditional discourse and morality of the day and may be interpreted as a rejection of women who enter into the military in the first place. Female soldiers' sexuality is placed in question precisely because their very presence in a male world represents a challenge and a threat hence the 'hesitation' in having intimate relationships with them. According to Cohen (2005), women's sexual deviance is threatening to men and the broader social system. There is a concern that women soldiers' sexuality will impact negatively on the broader cultural context of the military. This is consistent with the argument that sex and sex differences continue to be a disruptive force in the military despite dedication to the full integration of women (Carreira, 2006; Guttman, 1997; Sedibe, 2000).

According to John, intimate relationships between military instructors and recruits have catastrophic consequences for military principles such as discipline and respect. John further reported that women do not seem bothered by the sexual attentions of some instructors, and may even provoke this attention to cover their vulnerabilities related to physical fitness. This man's view is contrary to the frustrations reported by women around the country, where they accuse drill instructors of rape and sexual harassment (Carreira, 2006; Guttman, 1997; Sedibe, 2000).

For participants, intimate relationships with senior personnel are used to the benefit of women who are struggling to achieve success in the system on their own: 
Simon: Guys are strange creatures. Guys do that because they need something in return, and women know that, so they use power and they get qualifications. There are captains and majors in the infantory who have never, ever had even a section under them. They never had a platoon, they never had anything. All they do [is] make coffee and have sex with their seniors. I'm not saying all females. Don't get me wrong. There [are] a lot of good female soldiers. Unfortunately there is an element of ladies who [are] absolutely using the system

The following quote illustrates the skepticism with which women in the military are viewed and how their sexuality is problematised in order to undermine their authority:

Gerhard: I was in a course and the person who was in charge of the course, the instructor, she was a captain... she kept control over the whole exercise. She had a reputation for sleeping around. She wasn't a bad person but she had loose sexual relationships. And... looking at our constitution there's nothing wrong with it because she didn't... do what was wrong in terms of the military disciplinary code. It creates such a bad situation among all the guys who were on course [who] thought she was a joke. They undermined her authority under her nose and they made jokes in her face about it in a very subtle way that she couldn't take, but it wasn't good for discipline. Even looking at the way they operate on the fighting, running and shooting... few of them have the ability to keep that up.

Underlying the problematising of military sexuality is the traditional construction of men as sexually active and instinctively unfaithful, and expectations that women should have only one partner. Military women who do not behave in this mould are labeled negatively and undermined. The literature abounds with examples of this negative labeling of civilian women, underscoring the sexual double standard that applies internationally (Hollway, 1989; Holland et al., 1991). However, according to participants in this study, women in the military are more sexually active than civilians and appear to 'break' far more often with their traditional sexual roles. Most participants are therefore hesitant to have a relationship with women in the military. The following excerpt illustrates:

Thando: She goes on deployment somewhere and her boyfriend is staying. She's going to have a relationship or chances are she might have a relationship. And the fact that the military is like a little... small and 
almost all the relationships you have its... like everybody knows. They start getting names as prostitutes.

An interesting aspect of this discourse is that when female soldiers are away from their partners their reasons for having extra-marital or 'outside' intimate relationships are challenged, whereas for men it is acknowledged and understood as loneliness, or a result of being away from their families, highlighting the double standards in which male and female sexuality is judged. Therefore, this practice is accepted as a coping strategy for men.

John: For me it's not, it's not well if a lady goes out with a lot of guys. There's this, we carry this picture [that] a woman must be ladylike. And, I don't know, it's just, it's bad character. I don't know why, but then again for men it's different. I don't have a particular reason. I don't know if it's just a male thing, but I, okay I realise I'm a feeling person. What I feel is right, or my emotions help me think this is right and I go with that. The thing is, when I think about a lady doing it, I feel, no. But when I hear about the guy doing that, that feeling don't come.

It also appears that another reason for military men's hesitance to have relationships with military women, is that their intimate relationships may complicate their lives in the work environment. Military women in this context are further problematised as being potentially dangerous to men's domestic and work lives:

Sam: Some guys think that if I keep this thing... outside it's better. Maybe inside the camp there's somebody who knows my wife or my girlfriend, so I'd rather keep it outside, you see.

Another reason why men choose women in the community is that women in the military know one another. This restricts men's opportunities for having different women at different courses. This suggests that a group of women of a particular rank might communicate with each other and share not only the content of the course or courses, but also details about intimate relationships during these times.

There are also some benefits in having female sexual partners in the military for men. In particular, having a sexual relationship with a woman of senior rank (especially if it involves other historical power differences such as race) is 
reported by participants as signifying success for men. It is seen as a sign of masculinity:

Sam: I was a sergeant. I was in love with a captain, and she was white...we have to keep that thing secret. If the bosses ever found out that this white captain was going out with a coloured sergeant, they would have give[n] her gas (tough time) all the time, you see.

Keeping the secret was reported as exciting and challenging because the couple could not be seen in some public places together:

You really, you... can't wait for the next time you see her again, you see. So it was actually boosting the ego. It didn't last for that long. It was, it was... nice.

Ratele (2005) explains the secrecy of a sexual relationship between a black man and a white woman as developing out of a psychic and social reaction to the apartheid regime. For Simon to have a sexual relationship with a senior woman is articulated as a challenge which proves his masculinity:

I was a sergeant and I had a sexual encounter with a major and that was purely a challenge, that was to see if I can sleep with a major.

In line with Cohen's (2005) argument that women's sexual deviance is threatening to men and the broader social system, participants further perceive female soldiers' sexual desires as dangerous not only to men, but to the broader institutional context of the military. For example, intimate relationships between senior and junior personnel are classified as potentially disruptive of military principles such as discipline and respect. Blame for this is attributed to women joining the military, especially those who have stepped outside the traditional discourse that prescribes moral values for women. Guttman (1997) argues that the biological and sexual differences of men and women may always be challenging in the workplace, especially the integration of women in the military. Participants in this study also expressed concerns about the integration although (to some extent) they were committed to resolving it.

What underpins these gendered views is a traditional construction of men as instinctively unfaithful and continually sexually active. Female sexuality in the military milieu is expected to be 'morally correct'. If women behave otherwise, they 
are labeled negatively. This stigma also applies to female civilians (Holland et al., 1991; Hollway, 1989, 1996; Lesch, 2000; Shefer, 1999).

Contradicting the dominant discourse that denies women sexuality and desire is a discourse that portrays women's sexual response as significant for men, primarily as an index of male sexual prowess. As a result, knowledge about women's sexual desire is necessary for men to secure their sense of successful masculinity. This liberal discourse encouraging women to be sexually active does not take into account the power inequalities inherent in constructions of masculinity and femininity (Hollway, 1989; Van Wyk, 2004).

\section{Conclusions}

One of the key findings in this study regarding the construction of women in the military, is that women are not unambivalently welcomed in this institution. Three primary reasons emerge from this study: Firstly, the military is viewed as a traditional male environment because it is understood as risky and not suitable for women, who are tolerated mainly in lower-status administrative posts which are 'safer'. Some participants blamed government for allowing women in high-ranking positions which require qualities, perceived to be lacking in women, such as physical strength, braveness and leadership. This paper echoes similar studies that find gender and sex differences serve to explain different gender roles and power inequalities (Collinson \& Hearn, 1994; Flood, 2000; Shefer, 1999; Van Wyk, 2004). Secondly, women's active sexuality is perceived as problematic in the military as it is believed to impact negatively on the morale and discipline of soldiers. Female soldiers are accused of provoking men's sexual desires, especially those of seniors, in exchange for promotional favours. They are also blamed for putting the military at risk, because if they are in command and they have sexual relationships, this tends to undermine their leadership. Thirdly, the traditional discourse of women needing to be protected, as child-bearers, presents a paradox in the military context. By virtue of being women they have to be protected by men, and by joining the military suggests that they now want to protect the country and thus over-stepping the traditional task of males.

From this, it is evident there is a need to bring focus to bear on women's position in the military, primarily to change men's constructions of women in general, as well as to shift attitudes to female soldiers in a masculinist environment. As highlighted, men reject and stigmatise women who step outside of traditional roles, and in the military context, women may model on traditional male sexuality and other male practices, such as taking risks because of pressure in the military and 
through their own need to fit in with the men. Based on this, it is clear that interventions for men need to include looking at their perceptions and relations with women in the military. The other issue is how to demasculinise the military in order to allow women a rightful place. However, demasculising the military is quite a complex fraught in the sense that the military is inherently a masculinised institution. Will it be possible to demasculinise it? If so what does that mean? Can it be effective in its very goals if it is demasculinised? This is a subject of further investigation. Clearly, educational programmes, need to make provision for dialogue between men and women to facilitate openness regarding their own and each other's constructions of sexual identities, based on morale practices, safe sex and not on male prowess.

Although it has been beyond the scope of this study, the link between HIV/AIDS, the military and promiscuity, also highlights the value of deconstructing and challenging the institutionalised multiple partnering by men, by bringing to consciousness the implications of these practices for women (and men). There needs to be a stepping away from pathologising current sexual practices, and the construction of a politics of equality, respect and recognition. Therefore, repressive discourses such as women's subordination and stigmatisation (especially when they step out of prescribed roles) should be systematically challenged.

\section{References}

AIDS brief for sectoral planners and managers: Military sector (n.d.).

Agostino, K. 2003. Men, identity and military culture. In S. Tomsen \& M. Donaldson (eds.), Male trouble: Looking at Australian masculinities. Melbourne: Pluto Press: 108-131.

Barrett, F.J. 1996. The organisational construction of hegemonic masculinity: The case of the US Navy. Gender, Work and Organization, 3(3): 129-142.

Carreira, H. 2006. Assimilation, complicity, conformity and assertiveness: How military women respond to integration dilemmas. In: Proceedings of XVI World Congress of Sociology, Durban.

Chema, J.R. 1993. Arresting 'tailhook': The prosecution of sexual harassment in the military. Military Review, 140, Spring. 
Cheng, C. 1999. Marginalised masculinities and hegemonic masculinity: An introduction. The Journal of Men's Studies, 7(13): 295-314.

Cock, J. 1992. Women, the military and militarisation: Some questions raised by the South African case. In: Seminar No. 7, September, University of the Witwatersrand, Johannesburg.

Cock, J. 2001. Guns, violence and masculinity in contemporary South Africa. In R. Morrell (ed.), Changing men in Southern Africa. Pietermaritzburg: University of Natal Press: 43-46.

Cohen, C. 2005. From Bill Cosby to the down-low: Sex, panic and the quest for respectability in black communities. In: Proceedings of the Fifth International Association for the Study of Sexuality, Culture and Society Conference, San Francisco.

Cohn, C. 2000. How can she claim equal rights when she doesn't have to do as many push ups as I do? The framing of men's opposition to women's equality in the military. Men and Masculinities, 3(2): 131-151.

Collinson, D. \& Hearn, J. 1994. Naming men as men: Implications for work, organisation and management. Gender, Work and Organization, 1(1): 2-22.

Connell, R.W. 1992. A very straight gay: Masculinity, homosexual experience, and the dynamics of gender. American Sociological Review, 57(6): 735-752.

Connell, R.W. 1995. Masculinities. Cambridge: Polity Press.

Connell, R.W. 2000. The men and the boys. Berkeley: University of California Press.

Edley, N. \& Wetherell, M. 1997. Jockeying for position: The construction of masculine identities. Discourse and Society, 8: 203-217.

Enloe, C. 1988. Ethnic soldiers: State security in divided society. Athens: University of Georgia Press.

Flood, M. 2000. Lust, trust and latex: Why heterosexual young men don't use condoms. Unpublished doctoral thesis, The Australian National University. 
Foreman, M. (ed.). 1999. AIDS and men. London: Panos/Zed Books.

Gutmann, S. 1997. Sex and soldier: The road from Aberdeen. The New Republic, 216(8): 18 .

Heinecken, L. 2000. Security South Africa's future. Strategic Review for Southern Africa, 22(2): 76-102.

Holland, J., Ramazanoglu, C., Scott, S., Sharpe, S. \& Thomson, R. 1991. Pressure, resistance, empowerment: Young women and the negotiation of safer sex. Women risk and AIDS Project (WRAP). Paper 6. London: Tufnell Press.

Hollway, W. 1989. Subjectivity and method in psychology: Gender, meaning and science. London: Sage.

Hollway, W. 1995. Feminist discourse and women's heterosexual desire. In S. Wilkinson \& C. Kitzinger (eds.), Feminism and discourse: Psychological perspectives: $86-105$.

Hollway, W. 1996. Recognition and heterosexual desire. In D. Richardson (ed.), Theorising heterosexuality. Milton Keynes: Open University Press: 91-108.

Jung, H.Y. 1996. Phenomenology and body politics. Body and society, 2(2): 1-22.

Kanter, R.M. 1977. Men and women of the corporation. New York: Basic Books.

Klein, U. 1999. The contribution of the military and military discourse to the construction of masculinity in society. In: Proceedings of men and violence against women conference, Strasbourg, France.

Kümmel, G. 2002. When boy meets girl: The feminisation of the military. Current Sociology, 50(5): 615-639.

Lesch, E. 2000. Female adolescent sexuality in a coloured community. Unpublished doctoral thesis, University of Stellenbosch.

Lindegger, G. \& Durrheim, K. 2001. Men and AIDS. In C. R. Stones (ed.), Socio political and psychological perspectives on SA. New York: Nova Publishers: 229250. 
Lomsky-Feder, E. \& Rapoport, T. 2003. Juggling models of masculinity: RussianJewish immigrants in the Israeli Army. Sociological Inquiry, 73(1): 137-144.

Martino, W. 1999. 'Cool boys', 'party animals', 'squids' and 'poofters': Interrogating the dynamics and politics of adolescent masculinities in school. British Journal of Sociology of Education, 20(2): 239-263.

Morgan, D. 1994. Theatre of war: Combat, the military and masculinity. In H. Brod \& M. Kaufman (eds.), Theorising masculinities. Thousand Oaks: California: Sage Publications: 165-182.

Nagel, J. 1998. Masculinity and nationalism: Gender and sexuality in the making of nations. Ethnic \& Racial Studies, 21(2): 242-270.

Potts, A. 2001. The man with two brains: Hegemonic masculine subjectivity and the discursive construction of the unreasonable penis-self. Journal of Gender Studies, 10(2): 145-156.

Presidential Commission on the Assignment of Women in the Armed Forces. 1992. Report to the President. US Government Printing Office: Washington D.C.

Ratele, K. 2005. Proper sex, bodies, culture and objectification. Agenda, 2(63): 3242.

Republic of South Africa (RSA). 1996. The South African White Paper on Defence. Pretoria.

Sasson-Levy, O. 2003. Military, masculinity, and citizenship: Tensions and contradictions in the experience of blue-collar soldiers. Identities: Global Studies in Culture and Power, 10: 319-345.

Sedibe, P.R.F. 2000. Gender in the Department of Defence. Speech at the conference on making peace in Africa, peace through a gender lens. Pretoria.

Shefer, T. 1999. Discourses of heterosexual subjectivity and negotiation. Unpublished doctoral thesis, University of the Western Cape, Bellville.

Somerville, M. 2004. Tracing bodylines: The body in feminist poststructural research. In J. Joseph \& A. Valenzuela (eds.), International Journal of Qualitative Studies in Education, 17(1): 47-63. 
Steihm, J.H. 1980. Women and the combat exemption: Parameters, X(2), June.

Van Wyk, A. 2004. Discourses of love and relationship in the construction of a group of heterosexual, white Afrikaner women's sexuality. Unpublished masters thesis, University of the Western Cape, Bellville.

Weitzman, L.J. 1979. Sex role socialisation: A focus on women. California: Mayfield.

Williams, R. 1999. The role of the Truth and Reconciliation Commission in the reprofessionalisation of the South African Armed Forces. Strategic Review for Southern Africa, XXI(2): 40-72.

Woodward, R. 2000. Warrior heroes and little green men: Soldiers, military training, and the construction of rural masculinities. Rural Sociology, 65(4): 640-657. 